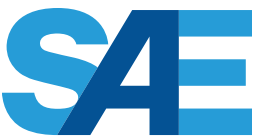

INTERNATIONAL

\title{
Fatigue Life Prediction of an Automotive Chassis System with Combined Hardening Material Model
}

\section{John George and Daniel Gross}

Honda R\&D Americas, Inc.

\author{
Hamid Jahed and Ali Roostaei \\ University of Waterloo
}

CITATION: George, J., Gross, D., Jahed, H., and Roostaei, A., "Fatigue Life Prediction of an Automotive Chassis System with Combined Hardening Material Model," SAE Technical Paper 2016-01-0378, 2016, doi:10.4271/2016-01-0378.

Copyright (C) 2016 SAE International

\begin{abstract}
The choice of an appropriate material model with parameters derived from testing and proper modeling of stress-strain response during cyclic loading are the critical steps for accurate fatigue-life prediction of complex automotive subsystems. Most materials used in an automotive substructure, like a chassis system, exhibit combined hardening behavior and it is essential to capture this behavior in the CAE model in order to accurately predict the fatigue life. This study illustrates, with examples, the strain-controlled testing of material coupons, and the calculations of material parameters from test data for the combined hardening material model used in the Abaqus solver. Stress-strain response curves and fatigue results from other simpler material models like the isotropic hardening model and the linear material model with Neuber correction are also discussed in light of the respective fatigue theories. A prediction of number of cycles for crack initiation of an automotive chassis system under a braking load cycle are compared to the results of physical tests in order to understand the merits and limitations of each model.
\end{abstract}

\section{Introduction}

The modeling of the inelastic behavior of materials is a crucial part of any fatigue simulation. Material properties determined from monotonic tensile tests are often used in design. For an isotropic hardening response, discrete monotonic stress and strain data points can be entered directly within the input deck of the Abaqus solver to define the plastic portion of the material curve. However, in service, most automotive systems experience cyclic loading, and experiments have shown that the cyclic plastic characteristics of metallic materials are different from their monotonic tensile characteristics [1]. The cyclic plastic behavior of metals is very complex in comparison and the cyclic data cannot be directly input into an FE solver like Abaqus. This study illustrates a method to calculate the cyclic material parameters for the Abaqus solver.
Figure 1 shows the rear chassis system used in a front-wheel drive passenger car. The subframe and the arms of the chassis system are made from various grades of steel, while the knuckle is made of cast aluminum. The amount of time and effort required to generate the cyclic properties for all the components is significantly higher compared to the monotonic tensile properties. In order to understand the benefits of generating the cyclic properties at a much higher cost, the fatigue test results of the suspension system under braking load cycle is compared with simulation results for material models generated from both monotonic and cyclic tests.

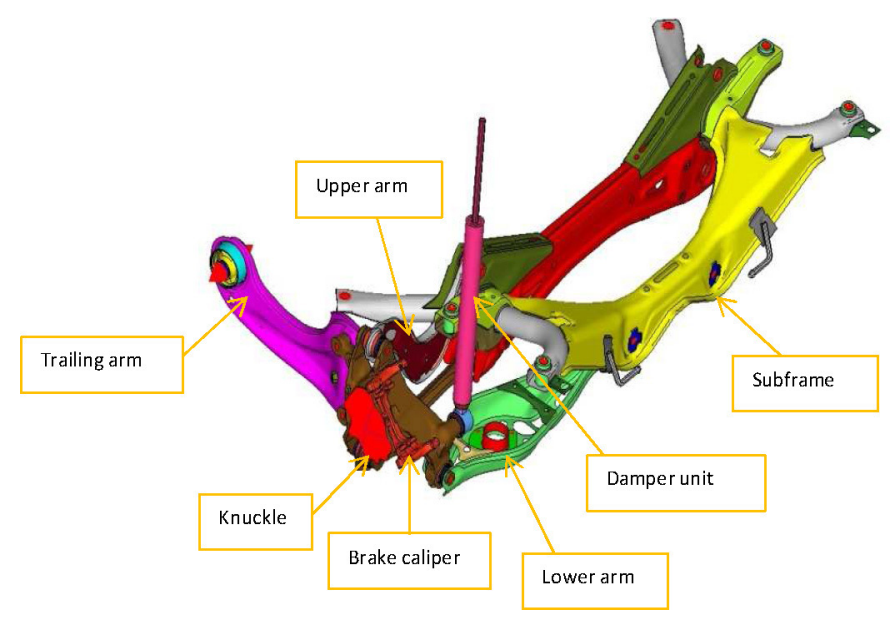

Figure 1. The rear-chassis system for a front-wheel drive passenger car.

\section{Material Characterization}

The various materials that are used in the chassis system shown in Figure 1 were tested to characterize its monotonic and cyclic properties. The geometry of the specimen used for the characterization is shown in Figure 2 (dimensions in $\mathrm{mm}$ ). All specimens were machined from sheets of $1.6 \mathrm{~mm}$ thickness. 


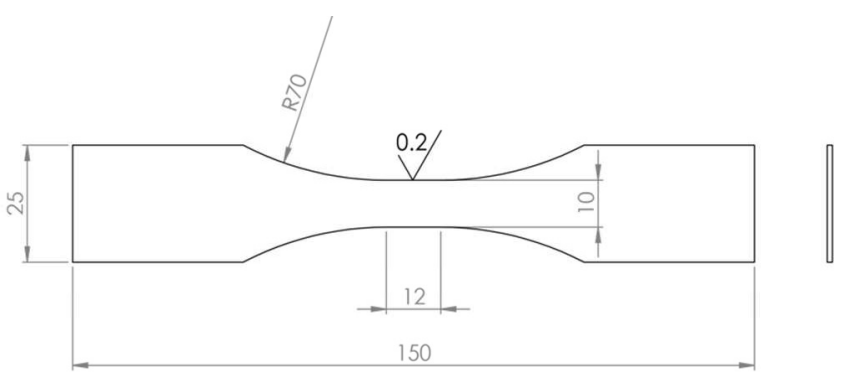

Figure 2. Geometry of the specimen used for material characterization. (All dimensions shown are in $\mathrm{mm}$ ).

\section{Cyclic Testing and Properties}

The cyclic tests were performed as per ASTM E606 standard [2] using the MTS 810 system with a load capacity of $50 \mathrm{kN}$. For each material tested, constant amplitude fatigue tests were conducted at different strain amplitudes ranging from $\pm 0.11 \%$ to $\pm 1.3 \%$.

Completely reversed strain conditions (R-ratio $=-1$ ) were used for all tests. Tests with higher strain amplitude were conducted under the MTS 810 system's strain-controlled mode at a frequency range applied at $1 \mathrm{~Hz}-3.5 \mathrm{~Hz}$ until failure was achieved. The loads were applied using a sine wave form. Some tests with long life and runouts were switched to load-controlled mode after stabilizing (reaching $\sim 50,000$ cycles) using a frequency of $20 \mathrm{~Hz}$. Failure criteria were considered to be a $50 \%$ drop of load in strain-controlled tests and final rupture in load-controlled tests.

Mid-life hysteresis loop data from the fatigue tests were used to determine the stable cyclic properties. Figure 3 shows the mid-life hysteresis loop of the material used in the lower arm of the suspension system at various strain amplitudes.

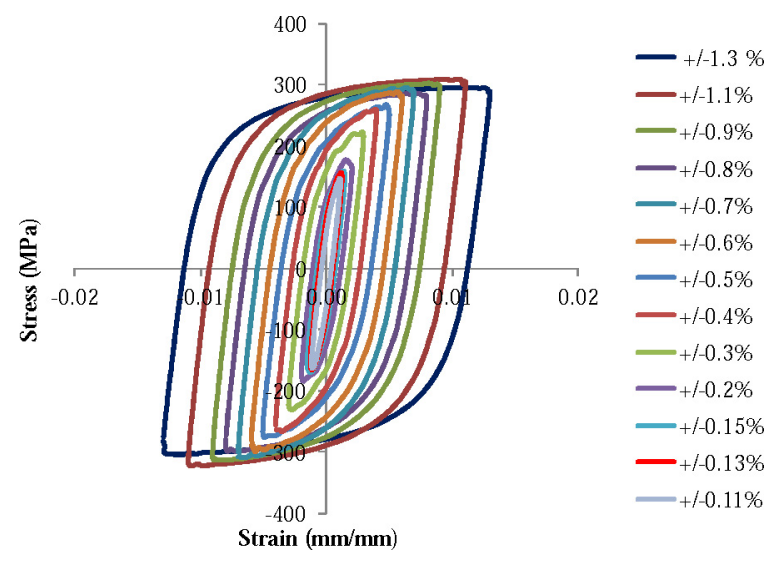

Figure 3. Mid-life hysteresis loop at various strain ranges.

The strain amplitudes and stress ranges of the mid-life loops from Figure 3 are shown in Table 1. From the strain and stress amplitudes, the cyclic stress-strain characteristics of the material are calculated according to the Ramberg-Osgood Eq. (1) [1].

$$
\varepsilon_{\mathrm{a}}=\varepsilon_{\mathrm{e}}+\varepsilon_{\mathrm{p}}=\frac{\sigma_{\mathrm{a}}}{\mathrm{E}}+\left(\frac{\sigma_{\mathrm{a}}}{\mathrm{K}^{\prime}}\right)^{1 / \mathrm{n}^{\prime}}
$$

Where $\varepsilon_{\mathrm{a}}$ is the strain amplitude, $\varepsilon_{\mathrm{e}}$ is the elastic strain, $\varepsilon_{p}$ is the plastic strain, $\sigma_{a}$ is the stress amplitude, E is the Young's modulus, $\mathrm{K}$ ' is the cyclic strength coefficient and n' is the cyclic hardening exponent. Values of K' and n' can then be obtained from a least squares fit of true stress amplitude and true plastic strain amplitude data in log-log scale as shown in Figure 4, where $\mathrm{K}$ ' is the intercept of the curve and n' is the slope. Figure 5 shows the calculated values of K', n' and the fit of the curve versus the test data from Table 1.

Table 1. True stress amplitudes and true plastic strain amplitudes.

\begin{tabular}{|c|c|c|c|c|c|c|}
\hline $\begin{array}{c}\text { Strain amp. } \\
\left(\mathrm{mm}^{\prime} / \mathbf{m m}\right)\end{array}$ & $\begin{array}{l}\text { Stress amp. } \\
\text { (MPa) }\end{array}$ & $\begin{array}{c}\text { True stress amp. } \\
\text { (MPa) }\end{array}$ & \begin{tabular}{|c|} 
True strain amp. \\
(mmimm)
\end{tabular} & $\begin{array}{c}\text { True plastic strain } \\
\text { amp. (mm/mm) }\end{array}$ & $\begin{array}{c}\text { Log tree stress } \\
\text { amp. (MPa) }\end{array}$ & $\begin{array}{c}\text { Log true plastic } \\
\text { strain amp. (mmimm) }\end{array}$ \\
\hline 0.013 & 299.5 & \begin{tabular}{|l|}
303.4 \\
\end{tabular} & \begin{tabular}{|l|l|}
0.01292 \\
\end{tabular} & 0.01144 & \begin{tabular}{|l|}
2.482 \\
\end{tabular} & -1.941 \\
\hline 0.011 & 315.3 & 318.8 & 0.01094 & 0.00958 & 2.504 & -2.019 \\
\hline 0.009 & 307.7 & 310.5 & 0.00896 & 0.00762 & 2.492 & -2.118 \\
\hline 0.008 & 305.1 & 307.5 & 0.00797 & 0.00654 & 2.488 & -2.184 \\
\hline 0.007 & 301.6 & 303.7 & 0.00698 & 0.00561 & 2.482 & -2.251 \\
\hline 0.006 & 294.0 & 295.8 & 0.00598 & 0.00455 & 2.471 & -2.342 \\
\hline 0.005 & 270.7 & 272.1 & 0.00499 & 0.00362 & 2.435 & -2.442 \\
\hline 0.004 & 263.7 & 264.7 & 0.00399 & 0.00282 & 2.423 & -2.549 \\
\hline $\begin{array}{l}0.001 \\
0.003 \\
\end{array}$ & 227.1 & 227.8 & $\begin{array}{l}0.000300 \\
0.00300\end{array}$ & $\begin{array}{l}0.00202 \\
0.00197\end{array}$ & 2.455 & $\begin{array}{l}-2.049 \\
-2.705\end{array}$ \\
\hline 0.002 & 181.0 & 181.3 & $\frac{0.00200}{0.00200}$ & 0.00111 & 2.258 & $\frac{2.057}{-2.957}$ \\
\hline 0.0015 & 164.6 & 164.9 & 0.00150 & 0.00071 & 2.217 & -3.149 \\
\hline 0.0013 & 161.0 & 161.2 & 0.00130 & 0.00058 & 2.207 & -3.239 \\
\hline 0.0011 & 155.5 & 155.7 & 0.00110 & 0.00039 & 2.192 & -3.404 \\
\hline
\end{tabular}

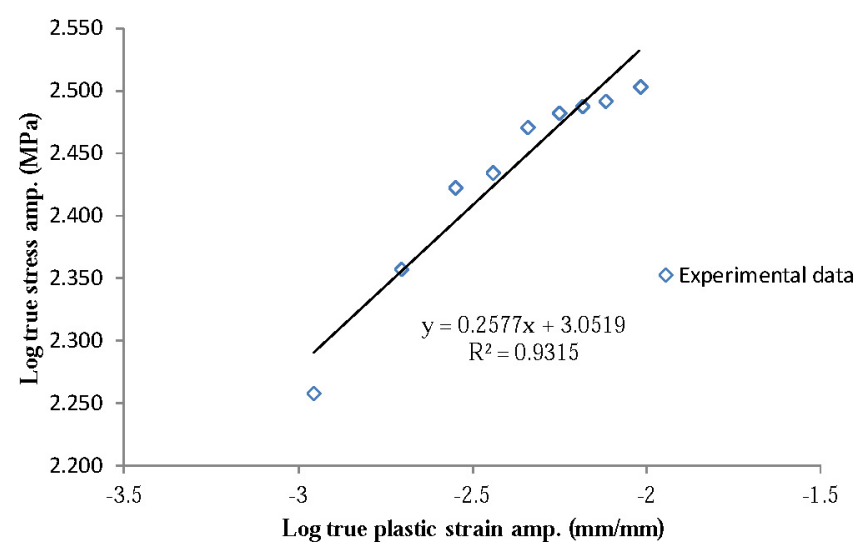

Figure 4. Least squares fit of true stress amplitude and true plastic strain amplitude in log-log scale.

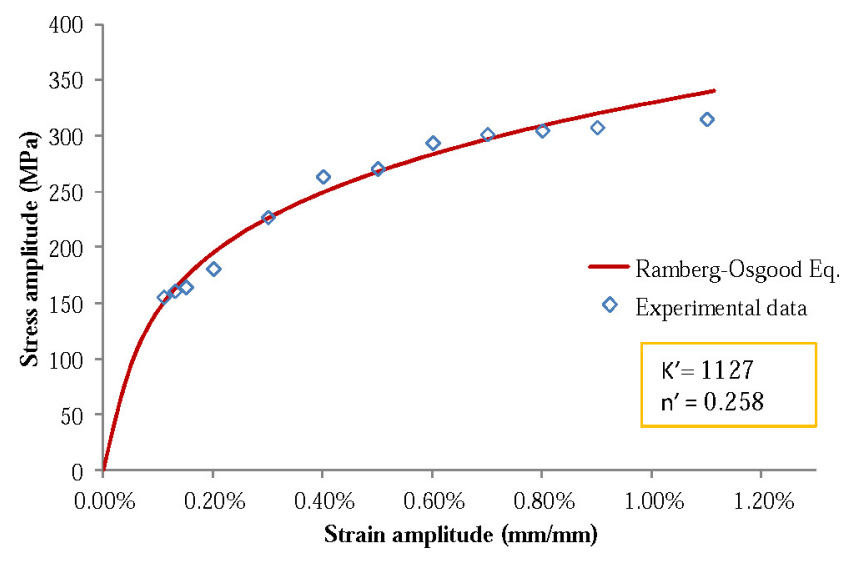

Figure 5. Plot showing the fit of the Ramberg-Osgood equation vs. test data.

\section{Material Model for Abaqus Solver with Cyclic Data}

Once the K' and n' values are obtained, the steady state cyclic stress-strain curve response of the materials at any strain range could be predicted using Masing's hypothesis, which states that the stabilized hysteresis loop may be obtained by doubling the cyclic stress-strain curve as shown in Eq. (2) [ $[\underline{3}]$.

$$
\Delta \varepsilon=\Delta \varepsilon_{\mathrm{e}}+\Delta \varepsilon_{\mathrm{p}}=\frac{\Delta \sigma}{\mathrm{E}}+2\left(\frac{\Delta \sigma_{\mathrm{a}}}{2 \mathrm{~K}^{\prime}}\right)^{1 / \mathrm{n}^{\prime}}
$$

The material response, as predicted by the cyclic hardening model cannot be explicitly input into Abaqus. To achieve a material response approaching the theoretical cyclic response, Abaqus uses a 
combined hardening model. This is an analytical response that defines the state of stress as a function of the back-stress tensor, $\alpha$. Eq. (3) and (4) [4] show this tensor defined as a function of the plastic strain and the three constants $\mathrm{C}, \sigma_{0}$ and $\gamma$.

$$
\begin{gathered}
f(\sigma-\alpha)=\sqrt{\frac{3}{2}\left(S-\alpha^{d e v}\right):\left(S-\alpha^{d e v}\right)} \\
\alpha=C \frac{1}{\sigma_{0}}(\sigma-\alpha) \varepsilon^{-p l}-\gamma \alpha \varepsilon^{-p l}
\end{gathered}
$$

These three constants must be defined by the user to target the cyclic material response. However, a more accurate method is to input the discrete stress and plastic strain data points of the upper hysteresis curve directly into the Abaqus input deck. Eq.(5) [4] shows that each data pair $\left(\sigma_{\mathrm{i}}, \varepsilon_{i}^{p l}\right)$ must be specified with the strain axis shifted to $\varepsilon_{\mathrm{p}}^{0}$.

$$
\varepsilon_{i}^{p l}=\varepsilon_{i}-\frac{\sigma_{i}}{E}-\varepsilon_{p}^{0}
$$

Where $\varepsilon_{p}^{0}$ is the plastic strain corresponding to the cyclic yield point of the upper hysteresis loop, the stabilized hysteresis loop calculated using Eq.(2) for a strain amplitude of $+/-0.25 \%$ and the corresponding $\left(\sigma_{1}, \varepsilon_{\mathrm{i}}^{\mathrm{pl}}\right)$ pair used for the Abaqus solver are shown in Figure 6.
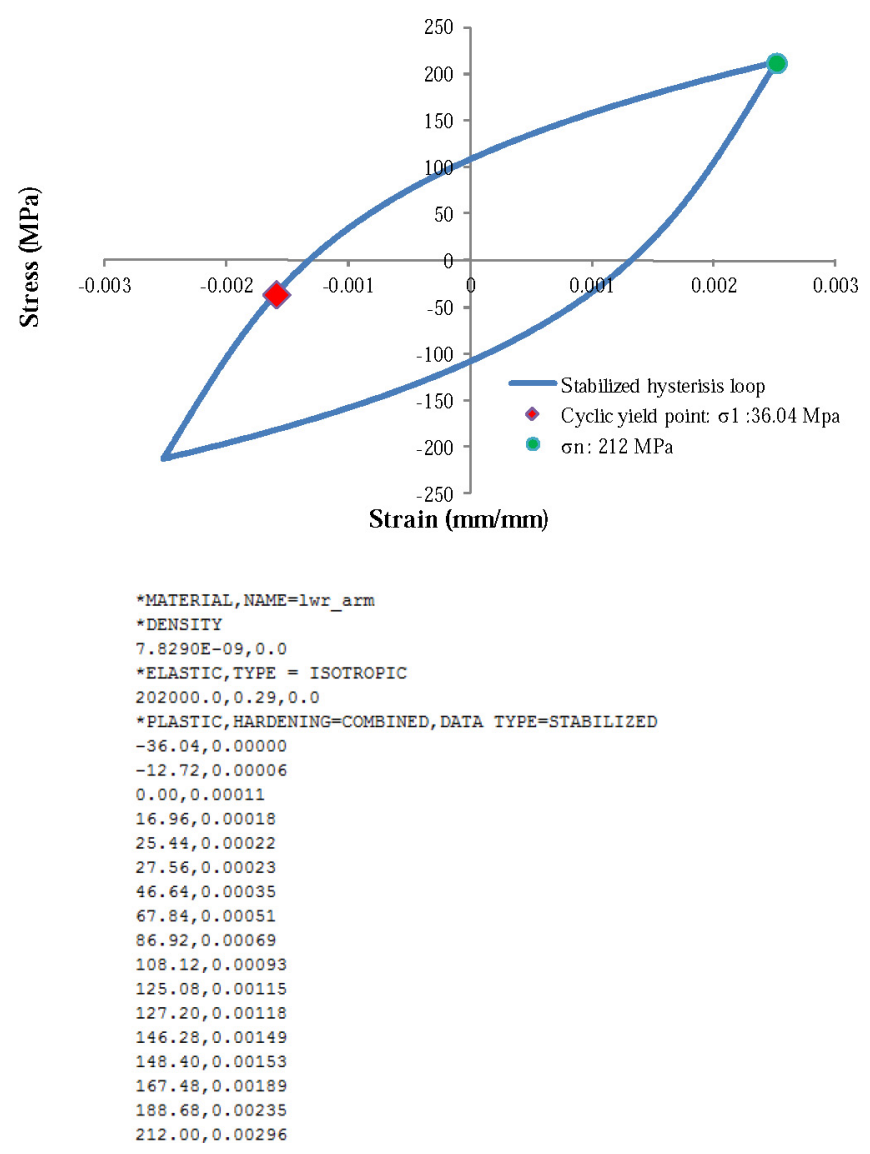

Figure 6. Stabilized hysteresis loop and the corresponding stress-strain pair used for the Abaqus solver.
Then, Abaqus can perform a curve fit analysis from these points to determine the combined hardening constants and output them to a . dat file. Figure 7 shows the $\mathrm{C}, \sigma_{0}$ and $\gamma$ parameters as calculated by the Abaqus solver for the data pair from Figure 6.

$$
\begin{array}{llc}
\text { ELASTIC } & \begin{array}{c}
\text { YOUNG'S } \\
\text { MODULUS }
\end{array} & \begin{array}{c}
\text { POISSON'S } \\
\text { RATIO }
\end{array} \\
& 2.02000 \mathrm{E}+05 & 0.29000
\end{array}
$$

NONLINEAR KINEMATIC/ISOTROPIC HARDENING MODEL

KINEMATIC COMPONENT

$$
\begin{aligned}
& \text { YIELD PARAMETER PARAMETER TEMPERATURE FIELD VARIABLES } \\
& 87.980 \quad 1.23415 \mathrm{E}+05 \quad 1047 .
\end{aligned}
$$

Figure 7. Combined hardening model parameters generated from Abaqus.

It is important to use the stabilized hysteresis loop at a strain range anticipated in the analysis to calculate the cyclic hardening parameters because the constants determined at a given strain range do not necessarily predict the hardening behavior at all strain ranges.

\section{Monotonic Testing and Properties}

The monotonic tension tests were conducted using test procedures as specified by the ASTM Standard E8-96a [ㅁ] $]$. The tests were conducted using the INSTRON 8874 system at a displacement rate of $10^{-2} \mathrm{~mm} \cdot \mathrm{sec}^{-1}$. Figure 8 shows the monotonic stress-strain data obtained from the material used for the lower arm.

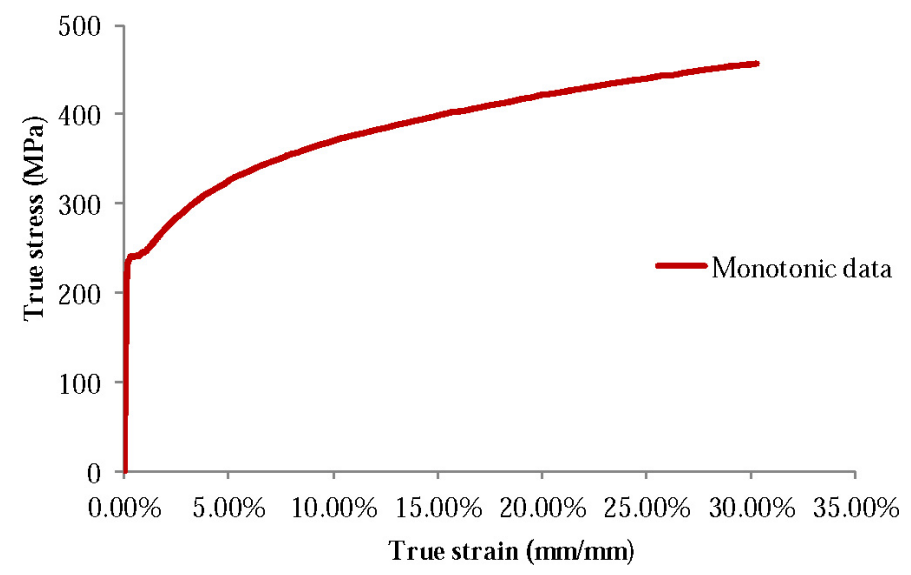

Figure 8. True stress -strain plot from monotonic test.

\section{Material Model for Abaqus Solver with Monotonic Data}

The default plasticity hardening model in Abaqus is the isotropic hardening model, and is calculated with the monotonic stress-strain data (igure 8). Unlike the combined hardening model with cyclic data, for the isotropic hardening model, discrete monotonic stress and strain data points defining the plastic region can be entered directly into the input deck of the Abaqus solver. The isotopic hardening model generated for the Abaqus solver from the stress-strain curve given in Figure 8 is shown in Figure 9. 
*MATERIAL, NAME=1wr_arm

*DENSITY

$$
7.85 \mathrm{E}-9 \text {, }
$$

*ELASTIC, TYPE=ISOTROPIC 210000 .

*plastic

$241.4,0.0000$

$243.5,0.0024$

$250.0,0.0057$

$251.9,0.0067$

$256.2,0.0083$

$262.3,0.0103$

$285.1,0.0192$

$322.3,0.0412$

$348.7,0.0650$

$374.8,0.0987$

$388.7,0.1230$

$400.3,0.1444$

$412.8,0.1721$

$422.2,0.1919$

$435.0,0.2246$

$447.9,0.2615$

$451.9,0.2748$

$457.7,0.2985$

Figure 9. Isotropic hardening model used in the Abaqus solver.

\section{Comparison of Material Data and Hardening Model}

Comparison of the data obtained from monotonic and cyclic tests for the lower arm material is shown in Figure 10. It shows that the material undergoes softening under cyclic load, and the cyclic yield of the material is much smaller than the monotonic yield. Since cyclic yielding occurs earlier than monotonic yielding, the plastic strain response predicted using cyclic data will be much higher than the data from monotonic tests.

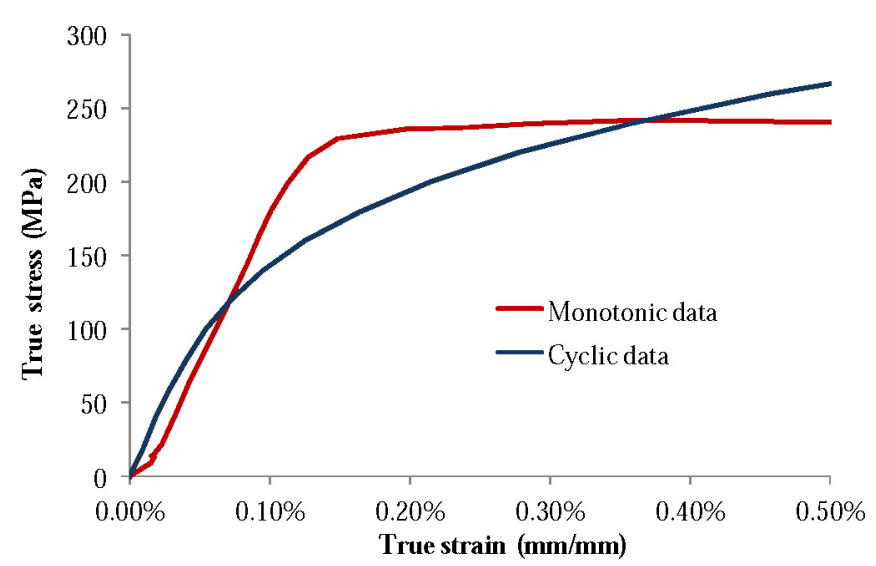

Figure 10. Comparison of the monotonic test data and cyclic test data.
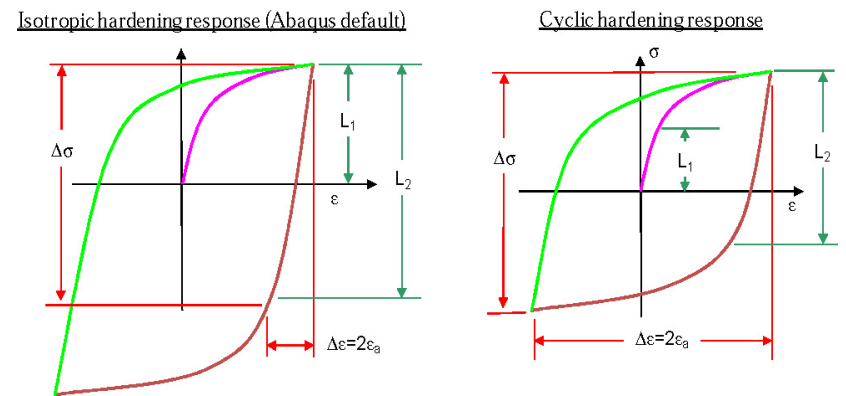

Figure 11. Comparison of the isotropic hardening response and cyclic hardening response.
The comparison of the isotropic hardening response (monotonic test data) and the cyclic hardening response (cyclic test data) is shown in Figure 11. For the isotropic hardening response, the linear portion of the cyclic stress-strain curve $\left(\mathrm{L}_{2}\right)$ is twice the length of the linear monotonic unloading response $\left(\mathrm{L}_{1}\right)$. While for the cyclic hardening model, the linear portion of the cyclic stress-strain curve $\left(\mathrm{L}_{2}\right)$, is twice the length of the linear monotonic loading response $\left(\mathrm{L}_{1}\right)$, resulting in a smaller $\left(\mathrm{L}_{2}\right)$ value compared to that obtained with the isotropic hardening model. Therefore, the cyclic hardening model takes into account the Bauschinger effect [ 6 ] while the isotropic hardening model does not. As seen in the above comparison, for a given stress range, $\Delta \sigma$, the strain range resulting from this loading, $\Delta \varepsilon$, is measurably different depending on which hardening model is used.

The differences in the material data and the hardening model can lead to significant discrepancies in stress-strain predictions when the isotropic hardening model from monotonic data is used for fatigue applications.

\section{The Linear Material Model with Neuber Correction}

The Neuber correction method is a commonly used approach in many fatigue applications [7]. In this method, a linear elastic material response analysis is done using an FE solution. Then, an estimate for the plastic true stress-strain state from the linear analysis runs in the fatigue solver using the Neuber formula (6) [] $]$.

$$
\sigma \varepsilon=\mathrm{Se}
$$

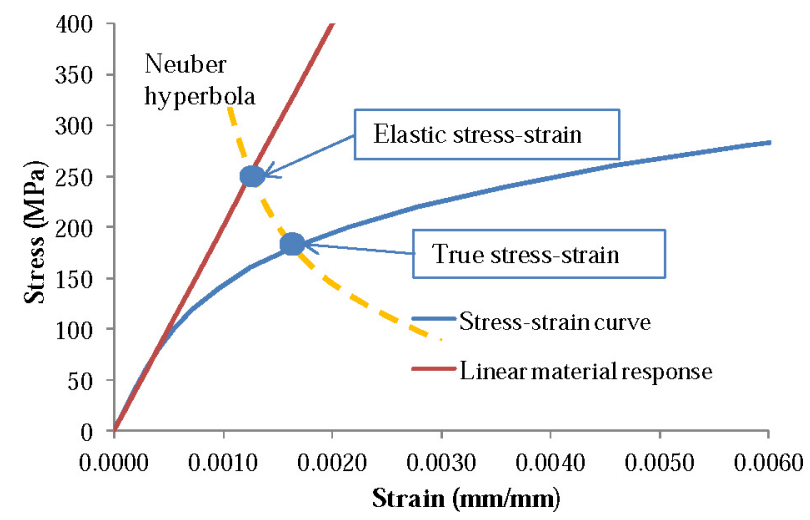

Figure 12. A Graphical representation of the Neuber method.

Where $\sigma, \varepsilon$ is the true stress and strain, while $\mathrm{S}$ and e are the elastic stress and strain, respectively. The Neuber method assumes that the product of stress and strain before and after redistribution is constant and is equal to the product of elastic stress and elastic strain. Figure 12 shows the application of the Neuber hyperbola graphically.

\section{CAE Analysis and Test Results}

The CAE analysis of the chassis system shown in Figure 1 was conducted with the braking load cycle using the isotropic model, cyclic hardening model and the Neuber correction method. Stressstrain responses of the chassis system were calculated using Abaqus while life (cycles to failure) from stress-strain output from the Abaqus solver were determined using nCode FE-FATIGUE. For the 
fatigue calculation with nCode, the critical plane method was used to combine the stress and strain, while Morrow's method was utilized for mean stress correction []].

\section{FE model}

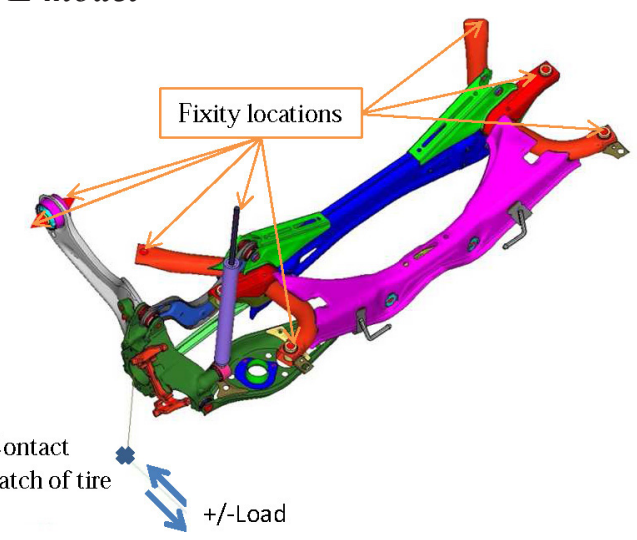

Figure 13. Loads and boundary conditions for the CAE model.

The rear suspension system shown in Figure 1 was used to study various material models. FE meshes for all sheet metal components were generated using shell elements and the knuckle/brake caliper was idealized using higher order tetra elements. The bushing components were created using hex elements and the rubber components of the bushings were modeled using the Neo-Hooke material model with a c10 parameter based on the hardness of the rubber [7]. The fixities of subframe mounting locations and the damper/trailing arm bolting locations were used as boundary conditions. The braking load time history was measured from the test track and the peak values in both fore and aft directions were applied as constant amplitude loads at the contact patch of the tire along the longitudinal axis of the vehicle as shown in Figure 13.

\section{Results from the CAE Analysis and Test}

Bench testing of the chassis system with the same load and fixity conditions as used in the simulation was conducted to evaluate the correlation with CAE analysis. The test results revealed a crack on the trailing arm as shown in Figure 14.

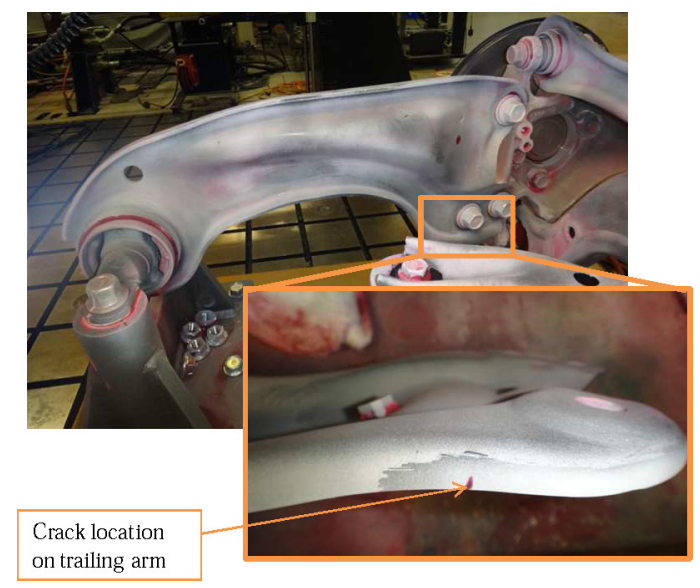

Figure 14. Test results showing the crack on the trailing arm.

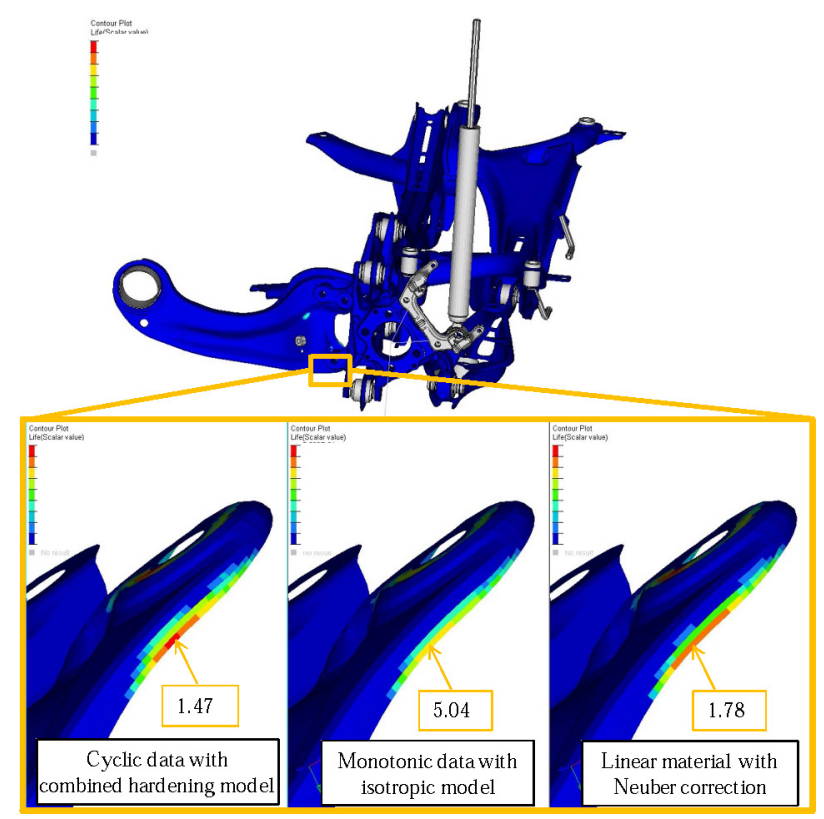

Figure 15. CAE results with various material models relative to test results.

The simulation results with all three material models also showed minimum life where the crack was detected on the trailing arm during the physical test. Figure 15 shows the minimum life of the trailing arm relative to the physical test results (cycles to crack initiation from $\mathrm{CAE} /$ cycles to crack initiation from the test).

Table 2 shows a summary of all the results. The cycles to failure presented are normalized with respect to the test results. (i.e., cycles to failure from test $=1$ )

Table 2. Summary of results.

\begin{tabular}{|c|c|c|c|c|}
\hline \multirow{2}{*}{ Location } & \multicolumn{3}{|c|}{$\begin{array}{c}\text { CAE results relative to test results } \\
\text { (Cycles to crack initiation) }\end{array}$} & $\begin{array}{c}\text { Test results } \\
(\sim \text { Cycles to crack } \\
\text { initiation) }\end{array}$ \\
\hline \multirow{2}{*}{$\begin{array}{c}\text { Trailing } \\
\text { arm }\end{array}$} & $\begin{array}{c}\text { Cyclic data with } \\
\text { combined hardening } \\
\text { model }\end{array}$ & $\begin{array}{c}\text { Monotonic data } \\
\text { with isotropic } \\
\text { model }\end{array}$ & $\begin{array}{c}\text { Linear material with } \\
\text { Neuber correction }\end{array}$ & \\
\cline { 2 - 4 } & 1.47 & 5.04 & 1.78 & 1.00 \\
\hline
\end{tabular}

\section{Summary of Results}

Results show that the combined hardening model generated from cyclic test data gave good correlation as compared to the test results, while the correlation from the isotropic model is very poor. Figure 10 and 11 show the isotropic model severely underestimates the strain response of the system due to the difference in the material data and hardening model itself. The study demonstrates that although it is much easier to generate the monotonic test data as compared to the cyclic data, using monotonic data in fatigue applications would lead to significant errors in strain response simulation and hence fatigue life predictions.

Results also show that the linear material model with Neuber plasticity correction gave reasonable correlation. It is noted here that this method is intended to be used for cases with low levels of plasticity resulting from a stress concentration. Judging by the cycles to failure information, it is implied that the system studied here experienced only low levels of plastic deformation. There could be other severe load cases where general yielding occurs in many areas and the linear model will not be able to capture load redistribution 
within components due to the onset of plastic deformation. It is not recommended to use the Neuber method for fatigue life prediction in such situations [10].

\section{References}

1. Boller, C. and Seeger, T., "Materials Data for Cyclic Loading," Elsevier Science Ltd., Vol 42, 1998

2. ASTM Standard E606-92, "Standard Practice for Strain Controlled Fatigue Testing", American Society for Testing and Materials, West Conshohocken, PA, 1997

3. Masing, G., "Eigenspannungen und Verfestigung beim Messing," in Proc. of 2nd Int. Congress of Appl. Mech., Zurich, 1926.

4. Abaqus Users' manual, ver 6.14, 2014

5. ASTM Standard E8-96a, "Standard Test Methods for Tension Testing of Metallic Materials", American Society for Testing and Materials, West Conshohocken, PA, 1997

6. Dowling Norman E, "Mechanical behavior of materials," Pearson Education, 2nd Edition, 1998
7. Trautwein, Thilo, "Numerical Validation and Application of the Neuber-Formula in FEA Analysis," presented at NAFEMS congress, May 2005

8. nCode DesignLife Theory Guide ver 10.1

9. Satoshi Ito, Koishikura Taro, and Suzuki Daichi, "Modeling and Analysis Techniques for Suspension Rubber Bushings", presented at SIMULIA Customer Conference, 2010

10. Song, G. and Tan, C., "Door Slam CAE Method Investigation," SAE Technical Paper 2015-01-1324, 2015, doi:10.4271/2015$\underline{01-1324}$

\section{Contact information}

\section{John George}

Honda R\&D Americas, Inc

21001 State Route 739

Raymond, OH, 43067

jgeorge@oh.hra.com

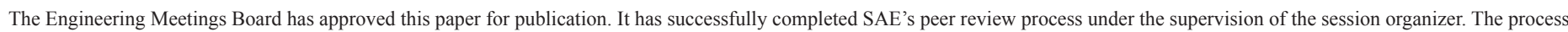
requires a minimum of three (3) reviews by industry experts.

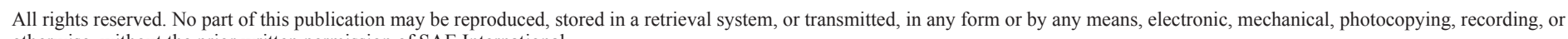
otherwise, without the prior written permission of SAE International.

Positions and opinions advanced in this paper are those of the author(s) and not necessarily those of SAE International. The author is solely responsible for the content of the paper.

ISSN 0148-7191

http://papers.sae.org/2016-01-0378

Replicated with permission by SAE, Copyright (c) 2016 SAE International. Further distribution of this material is not permitted without prior permission from SAE. 